\title{
Formation and development of scientific views about physiology of kidneys and water-balance in Novosibirsk
}

\section{Opinion}

The history of renal physiology in Siberia has begun with arrival to Novosibirsk the corresponding member of Russian Academy of Medical Sciences Alexander Grigor'evich Ginetzinsky (1895-1962), who headed the department of normal physiology of Novosibirsk Medical Institute from 1951 to 1955. Ginetzinsky AG has started to develop the new problem at that time a little studied in Russia - physiology of kidneys. By this period in renal physiology the theory stated by Canadian physiologist Verney E. ${ }^{1}$ He stated that in hypothalamus the central osmoreceptors are located, providing maintenance of the organism internal medium osmolality by changing of urine speed excretion: in conditions of hyperosmolality these receptors produce and secrete the antidiuretic hormone causing decrease of water excretion by kidneys. Ginetzinsky $\mathrm{AG}^{2}$ has come out with the assumption, that the central osmoreceptors could not regulate an osmotic homeostasis in all organism, therefore there should be peripheral osmoreceptors, perceiving osmotic shifts in any region of blood system. Checking of this hypothesis has been executed by the assistant of this department Larissa Konstantinovna Velikanova (1921-2010), subsequently the professor (1971), and Head of the Department of anatomy, physiology and hygiene of Novosibirsk Pedagogical Institute (1972-1987). She got evidence, that at fall of osmolality in the systemic circulation following water intake, the hypertensive solution infused into area of central osmoreceptors, did not cause the antidiuresis. The authors have explained this fact by a competition between the signals going from prospective peripheral osmoreceptors and opposite effect from central ones. And only after dissociation of nervous communications between peripheral and the centre by cutting a spinal cord, the excitation of central osmoreceptors with hypertensive solutions caused antidiuresis at any level of hydration of an organism. Thus, the short term of AG Ginetzinsky's work in Novosibirsk has crowned by the theory creation about osmoregulatory system of an organism which is presented with peripheral osmoreceptors, afferent nerves of a spinal cord, the centre, consisting from supraoptic and paraventricular hypothalamic nuclei (central osmoreceptors, by E Verney) and efferent link - Antidiuretic hormone (vasopressin) influencing the level of urination. This theory has laid down in a basis of numerous researches of AG Ginetsinsky's students who has worked in Novosibirsk.

The following period in development of renal physiology in Novosibirsk is dated from 1955 till 1970, and was actively developed under the guidance of the next Head of Department of normal physiology of Novosibirsk Medical Institute Ja D Finkinshtein (1922-2009). Under his guidance the employees have undertaken the experimental working out all parts of osmoregulatory reflex, beginning from receptors and finishing with renal mechanisms of its functioning. In particular, it has been found the existence of peripheral osmoreceptors in different organs and tissues, namely: in liver, ${ }^{3}$ kidneys, heart, lungs, a spleen, skeletal muscles, a gastrointestinal tract.
Volume 4 Issue 3 - 2017

\author{
Aizman RI, Subotyalov MA \\ Department of Anatomy, Novosibirsk State Pedagogical \\ University, Russia
}

\author{
Correspondence: Aizman RI, Novosibirsk State Pedagogical \\ University, Ministry of Education and Science of the Russian \\ Federation, Novosibirsk, 630I26, Russia, \\ Email aizman.roman@yandex.ru
}

Received: September II, 2017| Published: October 09, 2017

It was a little investigated the efferent link of osmoregulatory reflex, in particular, an action mechanism of antidiuretic hormone $(\mathrm{ADH})$ on kidneys. Schoolgirl of Ginetzinsky AG, subsequently the academician of the Russian Academy of Sciences, the Head of laboratory of physiological genetics of Scientific Research Institute of Cytology and Genetics of Siberian Branch of the Russian Academy of Sciences Ivanova Lyudmila Nikolaevna (Bornin 1929), has proved, that $\mathrm{ADH}$ causes increase in permeability of intercellular contacts in collective tubules due to the depolimerisation of the hyaluronic acid, therefore, increases the water reabsorption in distal nephron segment and decreases dieresis. ${ }^{4}$ In the subsequent she and her employees (Solenov EI, Lavrinenko VA, Melidi NN, Hegaj II, etc.), within several decades spent studying of molecular and genetic mechanisms of hormonal regulation of water-electrolyte balance, having opened the endocellular ways of ADH action in nephron and mechanisms of their regulation.

To the beginning of 70thyears of the XX-th century data began to appear, that except osmoregulatory mechanisms, kidneys play the important role in ionic regulation. One of the students of AG Ginetzinsky, the graduate from Novosibirsk Medical Institute Ju V Natochin (bornin 1932) Headed its laboratory in Scientific Research Institute of Evolutionary physiology and biochemistry of IM Sechenov in St.-Petersburg (1961), has found, that the solution with the raised concentration of sodium causes more expressed renalsodium excretion, than sodium-free solutions with the same osmotic concentration. ${ }^{5}$ Similar data have been received by A. Ja. Turner in Novosibirsk following intake of such solutions in the gastrointestinal canal. These works have laid down in a basis of studying of mechanisms of sodium regulation. In parallel and practically simultaneously in St.-Petersburg in laboratory of Ju. V. Natochin and in Novosibirsk under the guidance of Ja. D. Finkinshtejna studying of mechanisms of potassium regulation, and later - magnesium regulation has begun. To the middle of 80th years of the XX-th century on the basis of works of these researchers and their students there was a clear understanding about presence in an organism of reflex systems of sodium, potassium, and a magnesium homeostasis regulation (A Ja. 
Turner, RI Aizman, IV Pantjuchin, EM Tirishkina). The afferent part of these reflexes is presented by ion-selective receptors of a liver, ${ }^{6}$ from which the sensitive fibres of spinal nerves bear the information to the central part - supraoptic and paraventricular hypothalamic nuclei, and an efferent link includes except $\mathrm{ADH}$, a number of hormones (aldosterone, thyroxin, insulin, etc.). ${ }^{7}$ These views have received then acknowledgement and development in works of foreign researchers in the USA, Germany, Japan.

The following period in development of renal physiology in Novosibirsk is connected with opening of the Department of anatomy, physiology and hygiene in Novosibirsk Pedagogical Institute which was headed by Ginetzinsky's student professor LK Velikanova (from 1972), and since 1987 till nowadays-by professor RI Aizman. This stage is connected with studying of formation of mechanisms of regulation of an osmotic, ionic and volume homeostasis in ontogenesis not only in animals, but also in the people of different age, and the development of their reliability. The water-salt loading tests were developed at the Department, allowing to study response of kidneys of the people and animals of different age on water -salt loadings. It gave an essential push in progress of knowledge of kidneys functions, to estimate functional reserves of this homeostatic system. Confirmed by Ministry of Health of the USSR in 1983, these loading tests began to be applied widely in nephrology, space physiology and experimental researches. ${ }^{8}$ For the first time all stages of formation of mechanisms of regulation of water-mineral balance have been studiedon the person.

It has been proved, that in ontogenesis of the man the mechanisms of volume regulation (by 4years of a life), then osmotic (7-8years), and after (10-11years) - ionic are developed. ${ }^{9}$ Between them integration is formed, that provides first of all the restoration of an organism liquid environments volume (at hypovolemia) or osmolality (at hyperosmolarity). Specificity of ionic regulation is formed only by $10-11$ years of a child's life. At teenage age the system of regulation of ionic-osmotic homeostasis decreases its activity that expresses in deterioration of selectivity of the kidney response to different ion loadings, infringement of homeostatic indicators, higher reactance of kidney sodium excretion on $\mathrm{NaCl}$ in take. It has been established, that the important role in maintenance of a watermineral balance is played by the organs-depots, capable to deposit liquid and ions at their surplus in an organism or to give them to the systemic blood circulation at deficiency. Such ability is formed gradually in ontogenesis. ${ }^{10,11}$ Works of employees and post-graduate students of the Department, ${ }^{12-15}$ are devoted to study the influence of different environmental factors, types of the constitution, reception of medicinal substances, phytopreparations, etc. on functioning of the excretory system both in norm, and at various pathological conditions (a diabetes, nephritic insufficiency) and to develop ways of correction of homeostatic parametres in clinic.

Thus, by present time the Novosibirsk school of the renal physiology based by outstanding scientist AG Ginetzinsky, unites 4 generations of researchers which continue to study the watermineral regulatory system, molecular-genetic and age mechanisms of regulation of renal functions in norm and a pathology.

\section{Acknowledgements}

None.

\section{Conflict of interest}

Author declares that there is no conflict of interest.

\section{References}

1. Verney EB. Absorption and excretion of water; the antidiuretic hormone. Lancet. 1946;2(6431):739-744.

2. Ginetsinskiy AG. Physiological mechanisms of water-salt balance. USA: ML Publishing House (USSR Academy of Sciences); 1963. 427p.

3. Velikanova LK, Finkinshtein Ya D. Osmoreceptors of liver. Sechenov IM Physiological Journal of the USSR. USA; 1959;45(12):1472-1476.

4. Ivanova LN. Antidiuretic hormone and its role in the regulation of the osmotic regulation of urine. Physiology and Pathology of kidneys and water-salt metabolism. Ukraine: Naukova Dumka; 1974:35-45.

5. Natochin Y. Levels and mechanisms of integration kidney activity. Advances of Physiological Sciences. 1988;19(1):3.

6. Aizman RI, Finkinshtein Ya D. Osmo- and ion liver receptors. Sechenov IM Physiological Journal of the USSR. USA; 1976;62(1):130-138.

7. Finkinshtein Ya D, Aizman RI, Turner A Ya, et al. Reflex mechanism of the potassium homeostasis regulation. Sechenov IM Russian Journal of Physiology. 1973;59(9):1429-1437.

8. Orekhov KV, Aizman RI, Velikanova LK, et al. Developmental aspects of the study of water-salt metabolism and kidney functions in humans with the help of water and water-salt functional tests. Guidelines. Approved by the Ministry of Health of the USSR from 11-14/22-6. 1983.

9. Velikanova LK, Aizman RI. Developmental transformations of kidney functions. In: Physiology of Child Development. M Education. 1983. p. $177-195$.

10. Aizman RI. New views on the mechanisms of potassium homeostasis regulation. Nephrology and Dialysis. 2003;5(3):239-243.

11. Aizman RI. Formation of kidney function and water-salt metabolism in an ontogenesis. In: Bezrukikh MM, Farber DA, editors. Physiology of the Child. Spain: M Publ RAE; 2000. p. 186-200.

12. Aizman RI, Antonenko NP, Velikanova LK. Integration of mechanisms of regulation of water-salt balance following the growing water, salt and volume loads. Sechenov IM Physiological Journal of the USSR. 1980;66(9):1404-1411.

13. Gerasev AD, Svyatash GA, Lukanina SN, et al. Effect of natural zeolites on kidney functions and water-salt metabolism in rats. Ross Fiziol $\mathrm{Zh} \mathrm{Im}$ I M Sechenova. 2003;89(7):879-887.

14. Koroschenko GA, Gaydarova AP, Aizman RI, et al. The possibility of using of herbal remedies to maintain homeostasis at the pathology. Ukrainian Biopharmaceutical Journal. 2014;4(33):45-49.

15. Chorina Yu A, Gaydarova AP, Koroschenko GA, et al. Features of water-salt metabolism and kidney function in young men of different constitution types. Bulletin of the Novosibirsk State Pedagogical University; 2012;4:62-72. 